\title{
Correction to: The impact of time windows constraints on metaheuristics implementation: a study for the Discrete and Dynamic Berth Allocation Problem
}

\author{
Flávia Barbosa ${ }^{1}$ Priscila C. Berbert Rampazzo ${ }^{2} \cdot$ Anibal Tavares de Azevedo $^{2} \cdot$ Akebo Yamakami $^{3}$ \\ Published online: 20 June 2021 \\ (C) Springer Science+Business Media, LLC, part of Springer Nature 2021
}

Correction to: Applied Intelligence. https://doi.org/10.1007/s10489-021-02420-4

The original article unfortunately was published with a manuscript that is outdated.

The original article has been corrected.

Publisher's note Springer Nature remains neutral with regard to jurisdictional claims in published maps and institutional affiliations.

The online version of the original article can be found at https://doi.org/ 10.1007/s10489-021-02420-4

\footnotetext{
Flávia Barbosa

flavia@fe.up.pt

1 Faculdade de Engenharia da Universidade do Porto, Porto, Portugal

2 Faculdade de Ciências Aplicadas, Universidade Estadual de Campinas, Limeira, Brazil

3 Faculdade de Engenharia El'etrica e Computação, Universidade Estadual de Campinas, Campinas, Brazil
} 